\title{
Telework benefits and associated health problems during the long COVID-19 era
}

\author{
Marwa Zalat ${ }^{\mathrm{a}, \mathrm{b}}$ and Sarah Bolbol ${ }^{\mathrm{a}, *}$ \\ ${ }^{a}$ Department of Community, Environmental and Occupational Medicine, Faculty of Medicine, \\ Zagazig University, Zagazig, Egypt \\ ${ }^{\mathrm{b}}$ Department of Family and Community Medicine, Taibah University, Al Madinah City, Saudi Arabia
}

Received 1 May 2021

Accepted 18 August 2021

\begin{abstract}
.
BACKGROUND: Teleworking became a necessary practice as an alternative to office work during the long COVID-19 era. OBJECTIVES: To recognize the telework associated benefits and health problems and to assess the relationship between some teleworkers' characteristics, their health problems with job satisfaction and recuperation for promoting telework practices.

METHODS: A cross-sectional online survey was conducted among employees working remotely in different work sectors using a questionnaire assessing job satisfaction and recuperation.

RESULTS: Telework benefits included saving time and money (89.3\%), minimizing the COVID-19 spread (86.9\%), and balancing of work and life (63.4\%). Telework associated health problems included musculoskeletal (78.2\%), work-related stress $(65.9 \%)$, and visual problems $(47 \%)$. Telework job satisfaction was significantly higher among married male workers, working less than 40hs/week, and with previous remote working experience before COVID-19. On the other hand, married female teleworkers working more than 40hs/week and without previous remote working experience before COVID-19 had significantly more perceived fatigue and less recuperation. All teleworkers with reported health problems showed significantly more perceived fatigue and less recuperation.

CONCLUSIONS: More than half of the participants recommended continuing teleworking post-COVID-19 due to its benefits on their working and social life. Telework would enables the employers to adapt and satisfy the teleworkers' expectations to maintain their work and productivity.
\end{abstract}

Keywords: Pandemic, Saudi Arabia, job satisfaction, recuperation, working from home, coronavirus

\section{Introduction}

Telework practices are not a new concept and are commonly associated with high-skilled white-collar jobs, but a worldwide massive shift to teleworking occurred following the ongoing crisis of the COVID19 pandemic with various effects on the workers'

\footnotetext{
*Address for correspondence: Sarah Bolbol, Department of Community, Environmental and Occupational Medicine, Faculty of Medicine, Zagazig University, Zagazig, Egypt. E-mail: sar_bo@yahoo.com.
}

jobs and lives [1]. Some studies showed that working from home increased productivity, satisfaction, and allowed to better reconcile work-family duties. On the other hand, others felt teleworking, and the ensuing communication through digital platforms challenged the possibility to receive meaningful feedback and exchange ideas with co-workers and supervisors. Implementing telework in developed countries started several years ago, but little is known about the adoption of telework in developing countries [2, $3]$. The use of telework before the COVID-19 cri- 
sis varied substantially across countries, occupations sectors, and firms with tremendous growth during the crisis as a crucial strategy to mitigate the pandemic's health-related and economic consequences [4]. A wide range of work sectors either required or allowed their workers to perform home-based telework (HBT) [5]. Recent studies from Australia, Europe, and the USA emphasized the growth in implementing teleworking during the COVID-19 pandemic than before $[2,3]$. In developing countries with little adoption of teleworking before the COVID-19 crisis, implemented the HBT as a prompt response to this unprecedented situation without a contingency plan in various companies of different sectors, different sizes, and capacities [6].

Despite the fact that telework increases people's flexibility and autonomy, it also has recognized effects on health, which is still less studied [7]. Musculoskeletal problems, isolation, depression, and stress were the commonest health problems associated with telework as reported in different studies [8, 9]. In contrast, reduced commuting time, better worklife balance, and better control over schedule time were reported as telework benefits in other studies $[10,11]$.

Because of the long COVID-19 era with the increasing need for excessive downscaling of workspaces and keeping the telework practices to maintain productivity, this study aims to recognize benefits and health problems associated with telework practice among teleworkers in different work sectors in the Medinah region, Saudi Arabia, to assess the relationship between some participants' characteristics, their health problems with job satisfaction and recuperation among teleworkers, and to determine the preference for telework post-COVID-19 for promoting telework practices and enables the employers to be ready to adapt and satisfy the teleworkers expectations to maintain their work and productivity.

\section{Methods}

\subsection{Study design and setting}

A cross-sectional online survey was carried out from 1 April to 1 May 2021 among employees working remotely in different work sectors in the Medinah region, Saudi Arabia.

\subsection{Study participants, sampling, and procedures}

A semi-structured questionnaire was prepared based on previously published research articles related to teleworking and then designed electronically on Google Forms and shared via different social media at which the authors are members such as posts on Facebook, WhatsApp groups, Twitter, telegram with further snowball sampling to achieve maximum participation. The optimal sample size was calculated to be 385 participants by using OpenEpi software version 3.01 with a proportion of $50 \%, 5 \%$ margin of error, and a 95\% confidence interval [12]. All the fulltime/part-time paid employees that moved to work remotely as a result of the COVID-19 pandemic were legible to participate in the study.

\subsection{Tools of data collection}

The questionnaire consisting of 4 sections:

1. Questions about the socio-demographic and occupational characteristics such as age, gender, education, number of cohabitants, in particular minor children, type of workplace (e.g. public or private), full-time or part-time, previous remote working experience $[4,13]$. Also, questions asking about the benefits of telework as perceived by participants [14].

2. Health problems: Health assessed by questions asking about the commonest problems facing teleworkers gathered from previous research [15-17].

3. Telework job satisfaction: Assessed by the Utrecht Work Engagement Scale UWES-9S [18]. It is a self-report scale consisting of 9 questions grouped into three subscales: vigor (VI), dedication (DE), and absorption (AB). All items are scored on a seven-point scale ranging from 0 (never) to 6 (always). A total score was then calculated as the mean of the responses Higher values indicate more telework job satisfaction.

4. Recuperation: Assessed by 6 questions covering fatigue and rest/recuperation [19]. Responses were given on 5-point scales ranging from 0 (never) to 5 (very often), and one item scale was reversed (Do you feel you have recovered and are thoroughly rested when you start work in the morning). A total score was then calculated as the mean of the responses. Higher values indicate more perceived fatigue and less rest/recuperation. 
At the end of the electronic questionnaire participants, were asked about their opinion for recommending or refusing continuity of telework.

\subsection{Ethical considerations}

The online questionnaire included an informed consent form following the Declaration of Helsinki explaining the confidentiality of the obtained information and the purpose of the study. The necessary official permissions were obtained from the Taibah University Research Ethics Committee (Ref No \#TU20-017). The questionnaire was adequately translated into Arabic and then back-translated into English by a different language expert. A group of bilingual professionals assessed the Arabic versions for content validity. Cronbach's alpha was used to test reliability and was high for most of the questions.

\subsection{Data management}

Statistical analysis was done using SPSS version 25.0. Quantitative data were represented as a mean and standard deviation, and qualitative data were represented as frequencies and percentages. Descriptive statistics were used to determine the commonest health problems associated with teleworking. Normality was assessed using the Shapiro-walk test. The student's $t$-test was used as a test of significance to compare means across groups. The test results were considered significant when the $p$-value $\leq 0.05$.

\section{Results}

A total of 413 participants are $55.4 \%$ males and $44.6 \%$ females with a mean age of $36.49 \pm 5.02$ years. Most of them are married $69.2 \%$ and postgraduates $(53.8 \%)$. More than half of them $(57.1 \%)$ had more than 3 cohabitants at home and $60.3 \%$ were children less than 12 years. The majority of participants don't have caregivers at home $(72.2 \%)$ (Table 1).

The majority of teleworkers worked in the private sector (66.3) with a full-time job (83.5\%) and (67.8\%) of them had no remote working experience before the COVID-19. Most of the participants worked more than 40hs/week (69.5\%) with full data access (76\%). Participants worked both from home and at the workplace $(51.3 \%)$ with the same work tasks $(74.1 \%)$, they reported difficulty in focusing on work at home (71.2\%) (Table 2).
Table 1

Characteristics of the participants

\begin{tabular}{lc}
\hline Characteristics & No $(\%)$ \\
& 413 \\
\hline Age mean \pm SD & $36.49 \pm 5.02$ \\
Gender: & \\
$\quad$ Male & $229(55.4)$ \\
$\quad$ Female & $184(44.6)$ \\
Educational level: & \\
$\quad$ Graduate & $191(46.2)$ \\
$\quad$ Postgraduate & $222(53.8)$ \\
Marital status: & \\
$\quad$ Married & $286(69.2)$ \\
$\quad$ Unmarried & $127(30.8)$ \\
Number of cohabitants at home: & $177(42.9)$ \\
$\quad<3$ & $236(57.1)$ \\
$\quad \geq 3$ & \\
Presence of minor children less than 12 years? & $249(60.3)$ \\
$\quad$ Yes & $164(39.7)$ \\
$\quad$ No & \\
Presence of assistant, caregiver for elderly & \\
$\quad$ cohabitants or children: & $115(27.8)$ \\
$\quad$ Yes & $298(72.2)$ \\
$\quad$ No &
\end{tabular}

Table 2

Occupational characteristics of the participants

\begin{tabular}{|c|c|}
\hline Characteristics & $\begin{array}{c}\text { No }(\%) \\
413\end{array}$ \\
\hline \multicolumn{2}{|l|}{ Type of workplace: } \\
\hline Public & $139(33.7)$ \\
\hline Private & $274(66.3)$ \\
\hline \multicolumn{2}{|l|}{ Employment status: } \\
\hline Full-time & $345(83.5)$ \\
\hline Part-time & $68(16.5)$ \\
\hline \multicolumn{2}{|c|}{$\begin{array}{l}\text { Previous remote working experience before the } \\
\text { COVID-19 period: }\end{array}$} \\
\hline Yes & $133(32.2)$ \\
\hline No & $280(67.8)$ \\
\hline \multicolumn{2}{|l|}{ Amount of telework hours/week: } \\
\hline$<40 \mathrm{hs}$ & $126(30.5)$ \\
\hline$\geq 40 \mathrm{hs}$ & $287(69.5)$ \\
\hline \multicolumn{2}{|c|}{$\begin{array}{l}\text { Limited access to data when teleworking from } \\
\text { home: }\end{array}$} \\
\hline Yes & $99(24.0)$ \\
\hline No & $314(76.0)$ \\
\hline \multicolumn{2}{|l|}{ Difficulty in focusing on work at home: } \\
\hline Yes & $294(71.2)$ \\
\hline No & $119(28.8)$ \\
\hline \multicolumn{2}{|c|}{ Place of working during the COVID-19 period: } \\
\hline Completely working from home & $201(48.7)$ \\
\hline Working at both home and workplace & $212(51.3)$ \\
\hline \multicolumn{2}{|l|}{ Type of remote work: } \\
\hline Same as office work & $306(74.1)$ \\
\hline Different tasks & $74(17.9)$ \\
\hline Different salary & $33(8.0)$ \\
\hline
\end{tabular}

Study results showed that participants reported the benefits of telework including saving time and money $(89.3 \%)$, minimizing the spread of COVID-19 
Table 3

Benefits of telework practices

\begin{tabular}{lc}
\hline Benefits & No $(\%)$ \\
& 413 \\
\hline Save time and money on travel to work: & $369(89.3)$ \\
$\quad$ Yes & $44(10.7)$ \\
$\quad$ No & \\
Flexible hours to conduct work: & $241(58.4)$ \\
$\quad$ Yes & $172(41.6)$ \\
$\quad$ No & \\
Increased productivity: & $275(66.6)$ \\
$\quad$ Yes & $138(33.4)$ \\
$\quad$ No & \\
Greater independence in work commitments: & $294(71.2)$ \\
$\quad$ Yes & $119(28.8)$ \\
$\quad$ No & \\
Better balance of home and work life: & $262(63.4)$ \\
$\quad$ Yes & $151(36.6)$ \\
$\quad$ No & \\
Teleworking from home minimizes the spread of & \\
COVID-19: & $359(86.9)$ \\
$\quad$ Yes & $54(13.1)$ \\
$\quad$ No &
\end{tabular}

$(86.9 \%)$, increase independence $(71.2 \%)$ and productivity (66.6\%), balancing work and life (63.4\%), and flexible working hours $(58.4 \%)$ (Table 3 ).

Participants reported several health problems associated with telework including musculoskeletal (78.2\%), work-related stress (65.9\%), sleeping disorders $(51.1 \%)$, Visual problems $(47 \%)$, poor mental health $(45.5 \%)$, chronic diseases $(42.6 \%)$, and feelings of isolation (22.8\%) (Table 4).

When studying the association between some participants' characteristics with the telework job satisfaction we found that male workers, married, working half time, previous remote working experience before the COVID-19, and those working less than 40 hs/week showed higher job satisfaction. On the other hand, female teleworkers who were married, worked full time, had no previous remote working experience before the COVID-19, and worked more than $40 \mathrm{hs} /$ week, had significantly more perceived fatigue and less recuperation (Table 5).

Teleworkers without health problems showed significantly higher job satisfaction than those having health problems except for the feeling of isolation and work-related stress no significant differences were found. All teleworkers with reported health problems showed significantly more perceived fatigue and less recuperation (Table 6).

Asking the participants about their opinion for promoting telework after the COVID-19 era, $62.7 \%$ recommended continuing teleworking while the remaining $(37.3 \%)$ opposed to the telework due to
Table 4

Health problems associated with telework

\begin{tabular}{lc}
\hline Health problems & No (\%) \\
& 413 \\
\hline $\begin{array}{l}\text { Increases the development of musculoskeletal } \\
\text { problems (e.g. neck, shoulders, wrist, hand, }\end{array}$ \\
lumbar regions): \\
$\quad$ Yes \\
$\quad$ No & $323(78.2)$ \\
Induce feelings of isolation: & $90(21.8)$ \\
$\quad$ Yes & $94(22.8)$ \\
$\quad$ No & $319(77.2)$ \\
Chronic diseases (e.g. hypertension, high & \\
cholesterol, diabetes): & \\
$\quad$ Yes & $176(42.6)$ \\
No & $237(57.4)$ \\
Visual problems: & $194(47.0)$ \\
$\quad$ Yes & $219(53.0)$ \\
No & \\
Sleeping disorders: & $211(51.1)$ \\
Yes & $202(48.9)$ \\
No & \\
Work-related stress: & $272(65.9)$ \\
Yes & $141(34.1)$ \\
No & \\
Poor mental health (e.g. anxiety, depression): & $188(45.5)$ \\
Yes & $225(54.5)$ \\
No & \\
\hline
\end{tabular}

some causes as technical failures (93.5\%), increased work amount (92.2\%), difficult job management $(89.0 \%)$, lack of interaction with colleagues $(84.4 \%)$, increased distraction (81.8), and salary reduction $(80.5 \%)$.

\section{Discussion}

Before the COVID-19 pandemic, telework practices varied substantially across countries [20]. To date, few studies particularly in Arab countries have investigated teleworking. As nowadays telework has become a crucial and permanent feature of the future to sustain working life and keep the organization operational during the long COVID-19 era, so it was necessary to study its benefits and associated health problems to maximize job satisfaction, performance, and so gains for productivity.

In agreement with studies on characteristics of teleworkers [21, 22], this study showed that male employees are more likely to do telework than females. On the other hand, other studies dominate female teleworkers [23, 24]. These gender differences might be explained by different cultures and occupational sectors that implement telework. Other socio-demographic and job characteristics have been 
Table 5

Relation between telework job satisfaction, recuperation, and some of the participants' characteristics

\begin{tabular}{|c|c|c|c|c|}
\hline Characteristics & UWES-9S & $P$ value & Recuperation & $P$ value \\
\hline \multicolumn{5}{|l|}{ Gender: } \\
\hline Male & $36.77 \pm 9.50$ & \multirow[t]{2}{*}{$0.000^{*}$} & $17.48 \pm 1.58$ & \multirow[t]{2}{*}{$0.019^{*}$} \\
\hline Female & $29.70 \pm 8.66$ & & $18.05 \pm 3.30$ & \\
\hline \multicolumn{5}{|l|}{ Educational level: } \\
\hline Graduate & $33.70 \pm 6.99$ & \multirow[t]{2}{*}{0.879} & $17.61 \pm 2.50$ & \multirow[t]{2}{*}{0.366} \\
\hline Post-graduate & $33.56 \pm 10.82$ & & $17.84 \pm 2.52$ & \\
\hline \multicolumn{5}{|l|}{ Marital status: } \\
\hline Married & $35.86 \pm 8.96$ & \multirow[t]{2}{*}{$0.000^{*}$} & $18.04 \pm 2.02$ & \multirow[t]{2}{*}{$0.000^{*}$} \\
\hline Not married & $28.59 \pm 7.79$ & & $17.05 \pm 3.27$ & \\
\hline \multicolumn{5}{|c|}{$\begin{array}{l}\text { Previous remote working experience before the } \\
\text { COVID-19 period: }\end{array}$} \\
\hline Yes & $34.93 \pm 8.18$ & \multirow[t]{2}{*}{$0.047^{*}$} & $16.46 \pm 2.87$ & \multirow[t]{2}{*}{$0.000^{*}$} \\
\hline No & $33.003 \pm 9.65$ & & $18.34 \pm 2.07$ & \\
\hline \multicolumn{5}{|c|}{ Type of workplace: } \\
\hline Public & $34.77 \pm 10.93$ & \multirow[t]{2}{*}{0.071} & $17.45 \pm 2.86$ & \multirow[t]{2}{*}{0.100} \\
\hline Private & $33.04 \pm 8.21$ & & $17.88 \pm 2.31$ & \\
\hline \multicolumn{5}{|c|}{ Employment status: } \\
\hline Full-time & $33.10 \pm 9.53$ & \multirow[t]{2}{*}{$0.009^{*}$} & $17.95 \pm 2.55$ & \multirow[t]{2}{*}{$0.000^{*}$} \\
\hline Part-time & $36.27 \pm 7.09$ & & $16.63 \pm 1.95$ & \\
\hline \multicolumn{5}{|c|}{ Amount of telework hours/week: } \\
\hline$<40 \mathrm{hs}$ & $34.27 \pm 8.90$ & \multirow[t]{2}{*}{$0.031^{*}$} & $17.15 \pm 2.93$ & \multirow[t]{2}{*}{$0.002^{*}$} \\
\hline$\geq 40 \mathrm{hs}$ & $32.15 \pm 9.84$ & & $17.99 \pm 2.26$ & \\
\hline
\end{tabular}

*Significant $\leq 0.05 .{ }^{\dagger}$ Values are expressed as mean $\pm \mathrm{SD}, t$-test used as a test of significance.

Table 6

Relation between telework job satisfaction, recuperation, and the associated health problems

\begin{tabular}{|c|c|c|c|c|}
\hline Health problems & UWES-9S & $P$ value & Recuperation & $P$ value \\
\hline With musculoskeletal problems & $32.92 \pm 9.50$ & $0.003^{*}$ & $18.41 \pm 2.32$ & $0.000^{*}$ \\
\hline Without musculoskeletal problems & $36.15 \pm 7.74$ & & $15.32 \pm 1.49$ & \\
\hline With feelings of isolation & $34.09 \pm 5.00$ & 1.000 & $18.24 \pm 1.95$ & $0.026^{*}$ \\
\hline Without feelings of isolation & $33.45 \pm 10.16$ & & $17.58 \pm 2.64$ & \\
\hline With chronic diseases & $32.33 \pm 11.79$ & $0.014^{*}$ & $18.02 \pm 2.74$ & $0.047^{*}$ \\
\hline Without chronic diseases & $34.58 \pm 6.62$ & & $17.52 \pm 2.31$ & \\
\hline With visual problems & $31.80 \pm 10.54$ & $0.000^{*}$ & $18.85 \pm 1.73$ & $0.000^{*}$ \\
\hline Without visual problems & $35.24 \pm 7.57$ & & $16.75 \pm 2.68$ & \\
\hline With sleeping disorders & $32.46 \pm 8.97$ & $0.012^{*}$ & $18.32 \pm 2.36$ & $0.000^{*}$ \\
\hline Without sleeping disorders & $34.73 \pm 9.38$ & & $17.12 \pm 2.53$ & \\
\hline With work-related stress & $33.18 \pm 9.26$ & 0.176 & $18.24 \pm 2.13$ & $0.000^{*}$ \\
\hline Without work-related stress & $34.48 \pm 9.17$ & & $16.75 \pm 2.88$ & \\
\hline With poor mental health & $31.03 \pm 9.54$ & $0.000^{*}$ & $19.41 \pm 1.79$ & $0.000^{*}$ \\
\hline Without poor mental health & $35.79 \pm 8.40$ & & $16.33 \pm 2.15$ & \\
\hline
\end{tabular}

*Significant $\leq 0.05 .{ }^{\dagger}$ Values are expressed as mean $\pm \mathrm{SD}, t$-test used as a test of significance.

investigated in past studies with contradicting conclusions that need to be further explored in future research [25].

The present study reported various benefits of teleworking as saving time and money, minimizing the spread of COVID-19, increasing independence, flexible working hours balancing work and life. Similar results were obtained by Harris [26], who reported that telework is the solution to work-family balancing problems, and Tremblay [27], who appreciated the better organizations, the flexibility of teleworking hours, and saving time.

Recent studies $[28,29]$ reported the role of teleworking in limiting the spread of COVID-19 and reducing the number of newly infected cases. Also, other perceived telework benefits were reported in the previous study such as more concentration, fewer distractions, more autonomy, less cost, better work-time control, and so greater job motivation and satisfaction [30]. On contrary, other studies [31,32] demonstrated 
that telework may create a work-family conflict because of the blurring of boundaries between work and home time, and possible family member interference with work especially for those having minor children.

The current study demonstrated different health issues related to teleworking as musculoskeletal, work-related stress, sleeping disorders, visual problems, poor mental health, chronic diseases, and feelings of isolation. Similar findings were reported in previous studies [33-35] particularly musculoskeletal disorders which were linked to posture ergonomics risks usually associated with telework as awkward postures, repetitive movements, and a long period of continuous work without appropriate breaks which are important for musculoskeletal relaxation. Also, visual problems were reported from continuous use of video displays terminals while performing telework as shown by Nakazawa et al. [36]. Similarly, Thomée et al. [37] reported sleeping disorders and work-related stress, and Morahan-Martin and Schumacher [38] reported social isolation as a negative consequence of teleworking. However, today's easy and cheap communication technology via different audio/video conferencing facilitates social interaction, no matter where people are located [39].

In this study, we measured teleworking job satisfaction and recuperation on a specific scale and compared it to some participants' characteristics and associated health problems. Our results revealed that higher job satisfaction is common among male, married workers, working half time, previous remote working experience before the COVID-19, and those working less than $40 \mathrm{hs} /$ week. These findings could be explained by fact that Saudi Arabia was predominately a male-dominated country and males are usually given more responsibilities whether in life or job than their female counterparts and changing the office work to telework helped them more in facilitating their duties, managing their time and so better performance and job satisfaction. However, several previous studies reported higher job satisfaction for both male and female employees. These results might be related to different types of expectations from the job for male and female employees [40, 41].

In this study, female teleworkers, married, working full time, with no previous remote working experience before the COVID-19, and working more than $40 \mathrm{hs} /$ week had significantly more perceived fatigue and less recuperation. These findings might likely be due to being most of them work in the private sector with too much workload, having minor children less than 12 years without the availability of assistants or caregivers helping them. Moreover, as with starting the COVID-19 pandemic and associated lockdowns of schools, mandatory curfews, staying at home, and social isolation, all made the excessive burden on females at homes from increasing the number of her domestic duties in comparison to before COVID-19 besides adding a new load of distant education of minor children which is primarily done with the aid of mothers at homes.

As regards opinion toward preferring teleworking after COVID-19, more than half of our participants promoting telework. This finding could be explained by their higher job satisfaction and recuperation. Similarly, a study conducted by Buomprisco et al. [21] preferred telework and attributed that for being suitable for a variety of works and people of different ages, gender, and health status as motor disabled workers.

For those opposed permanent remote working attributed their reasons for technical failures, increased work amount, and salary reduction especially most of the participants working in the private sector and because of COVID-19 crisis, there was a ministerial resolution dated 6 April 2020 allowing the employers on either reducing employees' wages up to 40 percent for six months with a corresponding reduction in the work hours or placing them on paid annual leave, and or implement a period of unpaid leave [42]. Different telework perceptions might be related to the different country's affinity for technology, nature of occupational sectors, the availability and quality of Information Communication Technology infrastructure, and management culture [21].

\section{Limitations}

Being a cross-sectional design, we can't establish a cause-effect relationship, the study involves workers from one region, so the results can't be generalized across different regions or countries, this study was conducted during the COVID-19 crisis and did not examine whether the change in benefits, health problems and job satisfaction of teleworkers would outlast the pandemic. Further research is needed to examine the lasting impact of the COVID-19 pandemic on the use and perception of telework.

\section{Conclusions}

During the long COVID-19 era, telework practices become more important and represent one of 
the permanent features of the future to sustain economic activities and increase productivity. Various benefits of teleworking were reported as saving time and money, minimizing the spread of COVID-19, and flexible working hours. Musculoskeletal disorders, work-related stress, sleeping disorders, and visual problems were the highest problems reported. All teleworkers with reported health problems showed significantly more perceived fatigue and less recuperation. More than half of the participants promoting telework post-COVID-19 era. Results of this survey would be useful to promote the health of teleworkers and enables the employers to be ready to adapt and satisfy the teleworkers' expectations to maintain their work and productivity.

\section{Conflict of interest}

None to report.

\section{Funding}

This research did not receive any specific grant from funding agencies in the public, commercial, or not-for-profit sectors.

\section{References}

[1] Working anytime, anywhere: The effects on the world of work [Internet]. Publications Office of the European Union, Luxembourg, and the International Labour Office, Geneva; 2017. Available from: https:// www.eurofound.europa.eu/ publications/report/2017/ working-anytime-anywhere-theeffects-on-the-world-of-work

[2] Fana M, Milasi S, Napierala J, Fernandez-Macias E, Vazquez IG. Telework, work organisation and job quality during the COVID-19 crisis: a qualitative study. Joint Research Centre (Seville site); 2020.

[3] de Haas M, Faber R, Hamersma M. How COVID-19 and the Dutch 'intelligent lockdown' change activities, work and travel behaviour: Evidence from longitudinal data in the Netherlands. Transportation Research Interdisciplinary Perspectives. 2020; 6(100150): 100150.

[4] Shamshiripour A, Rahimi E, Shabanpour R, Mohammadian A (kouros). How is COVID-19 reshaping activity-travel behavior? Evidence from a comprehensive survey in Chicago. Transportation Research Interdisciplinary Perspectives. 2020; 7(100216): 100216.

[5] Nguyen MH, Armoogum J. Perception and preference for home-based telework in the COVID-19 era: A gender-based analysis in Hanoi, Vietnam. Sustainability. 2021; 13(6): 3179.

[6] Belzunegui-Eraso A, Erro-Garcés A. Teleworking in the context of the Covid-19 crisis. Sustainability. 2020; 12(9): 3662 .
[7] Crawford JO, MacCalman L, Jackson CA. The health and well-being of remote and mobile workers. Occup Med (Lond). 2011; 61(6): 385-94.

[8] Grant CA, Wallace LM, Spurgeon PC. An exploration of the psychological factors affecting remote e-worker's job effectiveness, wellbeing and work-life balance. Employee Relations. 2013; 35(5): 527-46. https:// doi.org/ 10.1108/ ER-08-2012-0059.

[9] Konradt U, Hertel G, Schmook R. Quality of management by objectives, task-related stressors and non-task-related stressors as predictors of stress and job satisfaction among teleworkers. European Journal of Work and Organizational Psychology. 2003; 12(1): 61-79. https:// doi.org/ 10.1080/ 13594320344000020

[10] Hilbrecht M, Shaw SM, Johnson LC, Andrey J. 'I'm home for the kids': Contradictory implications for work-life balance of teleworking mothers. Gend Work Organ. 2008; 15(5): 454-76.

[11] Nakrošienè A, Bučiūnienė I, Goštautaitè B. Working from home: characteristics and outcomes of telework. Int J Manpow. 2019 ; 40(1): 87-101.

[12] Dean AG, Sullivan KM, Soe MM. OpenEpi: Open Source Epidemiologic Statistics for Public Health, Version 3.01. 2013 [updated 2013/04/ 06]; Available from: www.OpenEpi.com

[13] Loo BPY, Wang B. Factors associated with home-based eworking and e-shopping in Nanjing, China. Transportation (Amst). 2018; 45(2): 365-84.

[14] Sánchez ND, Barragan LAA, Mário C, Rojas O. Perception and acceptance of telework by university students: a case study. 2014 [cited 2021 Mar 18]; Available from: https:// www.semanticscholar.org/paper/2d1a4ff8f5e6998d89a12e 670ece54733638be7b

[15] Wolkoff P. Indoor air humidity, air quality, and health - An overview. Int J Hyg Environ Health. 2018; 221(3): 376-90.

[16] Riccò M, Cattani S, Gualerzi G, Signorelli C. Work with visual display units and musculoskeletal disorders: A crosssectional study. Med Pr. 2016; 67(6): 707-19. https:// doi. org/ 10.13075/ mp.5893.00471

[17] Gálvez A, Martínez MJ, Pérez C. Telework and worklife balance: Some dimensions for organisational change. J Work Rights. 2011; 16(3-4): 273-97. https:// doi.org/ 10. 2190/ WR.16.3-4

[18] Schaufeli WB, Bakker AB, Salanova M. The measurement of work engagement with a short questionnaire: A crossnational study. Educ Psychol Meas. 2006; 66(4): 701-16.

[19] Aronsson G, Svensson L, Gustafsson K. Unwinding, recuperation, and health among compulsory school and high school teachers in Sweden. Int J Stress Manag. 2003; 10(3): 217-34

[20] Abulibdeh A. Can COVID-19 mitigation measures promote telework practices? J Labor Soc. 2020; 23(4): 551-76.

[21] Sener IN, Bhat CR. A copula-based sample selection model of telecommuting choice and frequency. Environ Plan A. 2011; 43(1): 126-45. https:// doi.org/ 10.1068/ a43133

[22] Buomprisco G, Ricci S, Perri R, De Sio S. Health and telework: New challenges after COVID-19 pandemic. Eur J Environ Public Health. 2021; 5(2): em0073. https:// doi.org/ 10.21601/ ejeph/ 9705

[23] Sullivan C, Lewis S. Home-based telework, gender, and the synchronization of work and family: Perspectives of teleworkers and their co-residents. Gend Work Organ. 2001; 8(2): 123-45. https:// doi.org/ 10.1111/ 1468-0432.00125

[24] Paleti R. Generalized Extreme Value models for count data: Application to worker telecommuting frequency choices. 
Trans Res Part B: Methodol. 2016; 83: 104-20. https:// doi.org/ 10.1016/ j.trb.2015.11.008

[25] Asgari H, Jin X, Mohseni A. Choice, frequency, and engagement: Framework for telecommuting behavior analysis and modeling. Transp Res Rec. 2014; 2413(1): 101-9. https:// doi.org/ 10.3141/ 2413-11

[26] Harris L. Home-based teleworking and the employment relationship: Managerial challenges and dilemmas. Pers Rev. 2003; 32(4): 422-37.

[27] Tremblay D-G. Telework: A new mode of gendered segmentation? Results from a Study in Canada. Can J Commun [Internet]. 2003 [cited 2021 Apr 20]; 28(4). Available from: https:// www.cjc-online.ca/ index.php/ journal/ article/ view/ 1393

[28] Gourinchas P-O. "flattening the pandemic and recession curves" [Internet]. Berkeley.edu. [cited 2021 Apr 20]. Available from: https:// clausen.berkeley.edu/ wp-content/ uploads/ 2020/ 03/ COVID_2b.pdf

[29] Nicola M, Alsafi Z, Sohrabi C, Kerwan A, Al-Jabir A, Iosifidis $\mathrm{C}$, et al. The socio-economic implications of the coronavirus pandemic (COVID-19): A review. Int J Surg. 2020; 78: 185-93.

[30] Wheatley D. Employee satisfaction and use of flexible working arrangements. Work Employ Soc. 2017; 31(4): 567-85.

[31] Adkins CL, Premeaux SF. Spending time: The impact of hours worked on work-family conflict. J Vocat Behav. 2012; 80(2): 380-9.

[32] Myers KR, Tham WY, Yin Y, Cohodes N, Thursby JG, Thursby MC, et al. Unequal effects of the COVID-19 pandemic on scientists. Nat Hum Behav. 2020; 4(9): 880-3.

[33] Hoe VCW, Urquhart DM, Kelsall HL, Sim MR. Ergonomic design and training for preventing work-related musculoskeletal disorders of the upper limb and neck in adults. Cochrane Database Syst Rev. 2012; (8): CD008570. https:// doi.org/ 10.1002/ 14651858.CD008570.pub2
[34] Davis KG, Kotowski SE, Daniels D, Gerding T, Naylor J, Syck M. The Home Office: Ergonomic Lessons From the "New Normal". Ergonomics In Design. 2020; 28(4): 4-10.

[35] Gerding T, Syck M, Daniel D, Naylor J, Kotowski SE, Gillespie GL, Freeman AM, Huston TR, Davis, KG. An assessment of ergonomic issues in the home offices of university employees sent home due to the COVID-19 pandemic. Work. 2021; 68(4): 981-92.

[36] Nakazawa T, Okubo Y, Suwazono Y, Kobayashi E, Komine $\mathrm{S}$, Kato N, et al. Association between duration of daily VDT use and subjective symptoms. Am J Ind Med. 2002; 42(5): 421-6. https:// doi.org/ 10.1002/ ajim.10133

[37] Thomée S, Eklöf M, Gustafsson E, Nilsson R, Hagberg M. Prevalence of perceived stress, symptoms of depression and sleep disturbances in relation to information and communication technology (ICT) use among young adults - an explorative prospective study. Comput Human Behav. 2007; 23(3): 1300-21.https:// doi.org/10.1016/j.chb.2004.12.007

[38] Morahan-Martin J, Schumacher P. Loneliness and social uses of the Internet. Comput Human Behav. 2003; 19(6): 659-71.

[39] Turetken O, Jain A, Quesenberry B, Ngwenyama O. An empirical investigation of the impact of individual and work characteristics on telecommuting success. IEEE Trans Prof Commun. 2011; 54(1): 56-67. https:// doi.org/ 10.1109/ TPC.2010.2041387

[40] Oshagbemi T. Gender differences in the job satisfaction of university teachers. Women Manag Rev. 2000; 15(7): 331-43.

[41] Azim MT. Gender, marital status and job satisfaction an empirical study. International Review of Management and Business Research, 2013; 2(2): 488-98.

[42] Ministry of Human Resources and Social Development. Kingdom of Saudi Arabia. Available at https:// www.misa.gov.sa/ media/ 1214. Last accessed 21/ 4/ 2021. 